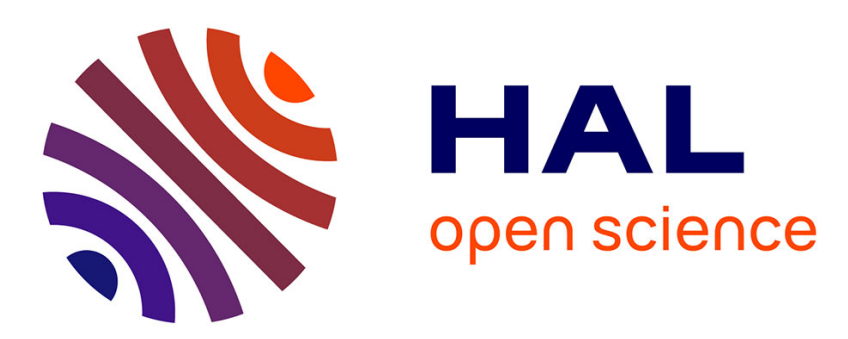

\title{
A quantitative evaluation of the contribution of crustal rocks to the shear-wave splitting of teleseismic SKS waves
}

\author{
Guilhem Barruol, David Mainprice
}

\section{> To cite this version:}

Guilhem Barruol, David Mainprice. A quantitative evaluation of the contribution of crustal rocks to the shear-wave splitting of teleseismic SKS waves. Physics of the Earth and Planetary Interiors, 1993, 78, pp.281 - 300. 10.1016/0031-9201(93)90161-2 . hal-01389713

\section{HAL Id: hal-01389713 \\ https://hal.univ-reunion.fr/hal-01389713}

Submitted on 29 Oct 2016

HAL is a multi-disciplinary open access archive for the deposit and dissemination of scientific research documents, whether they are published or not. The documents may come from teaching and research institutions in France or abroad, or from public or private research centers.
L'archive ouverte pluridisciplinaire HAL, est destinée au dépôt et à la diffusion de documents scientifiques de niveau recherche, publiés ou non, émanant des établissements d'enseignement et de recherche français ou étrangers, des laboratoires publics ou privés. 


\title{
A quantitative evaluation of the contribution of crustal rocks to the shear-wave splitting of teleseismic SKS waves
}

\author{
Guilhem Barruol *, David Mainprice \\ Laboratoire de Tectonophysique, Université Montpellier II, F-34095 Montpellier, Cedex 05, France
}

(Received 5 February 1992; revision accepted 30 June 1992)

\begin{abstract}
The seismic (elastic) properties of the crust have been modelled using hypothetical polycrystals with typical crustal compositions and commonly measured petrofabrics. This modelling allows us to better evaluate and quantify the crustal contribution to splitting of teleseismic SKS-waves. Mafic rocks such as anorthosite or pyroxene-bearing gabbros have complex S-waves properties, i.e. with small shear-wave anisotropies $(<3 \%)$ and without clear relationships between the fast shear-wave polarization plane orientations and the fabric. On the other hand foliated felsic rocks such as gneisses or schists and mafic rocks such as amphibole-bearing gabbros are strongly birefringent (anisotropies greater than 5\%) and exhibit clear relationships with the structure. Biotite and amphibole preferred orientations clearly play a major role in shear-wave splitting in crustal rocks. We show strong correlations between the orientation of the foliation and the amplitude of the delay time. Maximum delay time is systematically observed for waves propagating parallel to the foliation. The fast shear-wave is furthermore polarized parallel to the foliation plane. We calculate a delay time of about $0.1-0.2 \mathrm{~s}$ per $10 \mathrm{~km}$ of crustal rocks.
\end{abstract}

\section{Introduction}

To better constrain the magnitude and orientation of the mantle anisotropy using splitting of teleseismic SKS-waves it is important to evaluate the crustal contribution to the observed total delay time. A direct way is to measure the delay from splitting of PmS waves (e.g. McNamara et al., 1989). In this paper, we propose an alternative approach: we calculate the S-wave seismic properties of hypothetical rocks and then we estimate the delay time for various typical crustal rocks with various orientations. We show that the crust in some specific cases may generate a significant splitting.

Seismic anisotropy of rocks is increasingly investigated and shows relationships with the structure (foliation, lineation) (see reviews by Kern (1990) and Fountain and Christensen (1989)). This link between deformation fabric and seismic

\footnotetext{
* Corresponding author
}

properties may provide a powerful method to derive tectonic interpretations from seismic data. From this point of view, shear-waves propagating through anisotropic media are particularly interesting because their analysis may be very informative. A shear-wave crossing an anisotropic medium splits into two shear-waves which propagate at different velocities and which are perpendicularly polarized (e.g. Crampin, 1985). This phenomenon is called birefringence. From threecomponent seismic records, one can extract: (1) the arrival time of each shear-wave; (2) the difference in arrival times (or delay time) between the two perpendicularly polarized waves which is a function of the thickness and intrinsic anisotropy of the anisotropic medium; (3) the orientation of the polarization planes which reflects the orientation of the structure.

Seismic anisotropy, and hence shear-wave splitting, has two different origins: microcrack-induced anisotropy and anisotropy due to mineral lattice preferred orientation (LPO). Crack-related anisotropy obviously plays an important role 
at low effective confining pressure or at high pore fluid pressure and may have a dominant role in the upper crust (e.g. Peacock et al., 1988; Crampin et al., 1990). In the middle to lower crust, LPO is expected to be the major cause of seismic anisotropy. To better evaluate the shear-wave delay time due to the lower and middle crust, we focus in this paper on the effect of rock petrofabric on shear-wave splitting.

In the first part of this paper, we review the birefringence data obtained through direct laboratory measurements. This has some implications for anisotropy magnitude and orientation in crustal rocks. in the second part, combining single crystals' stiffness coefficients and measured petrofabrics, we calculate the seismic properties of hypothetical rocks with typical LPO and modal compositions. We show that the results obtained by the calculations are in complete agreement with the direct velocity measurements. In the last section of this study we evaluate the delay time due to the crust on typical SKS records, using simple crustal structures and realistic lithologies.

\section{Birefringence of crustal rocks from direct ve- locity measurements}

Although many laboratory S-wave measurements have been carried out over the last 25 years, very few studies have investigated shearwave splitting (SWS), i.e. measured seismic velocities of the two perpendicularly polarized S-waves for each propagating direction. Here we present the birefringence data available in the literature. All measurements were carried out in the structural reference frame $(X, Y$ and $Z, X Y$ being the foliation plane, $X$ representing the lineation and $Z$ the foliation pole) parallel to the three structural directions, as shown in Fig. 1. For rocks from the Santa Rosa Mylonite zone (Kern and Wenk, 1990) SWS was only measured along the $X$ - and $Z$-axis. For metamorphic rocks (Christensen, 1966), only one seismic velocity was measured along the $Z$-axis because splitting was not significant. Rocks studied by Barruol et al. (1992) and by Barruol and Kern (1993) were, respectively, sampled in the Saint Barthélémy massif

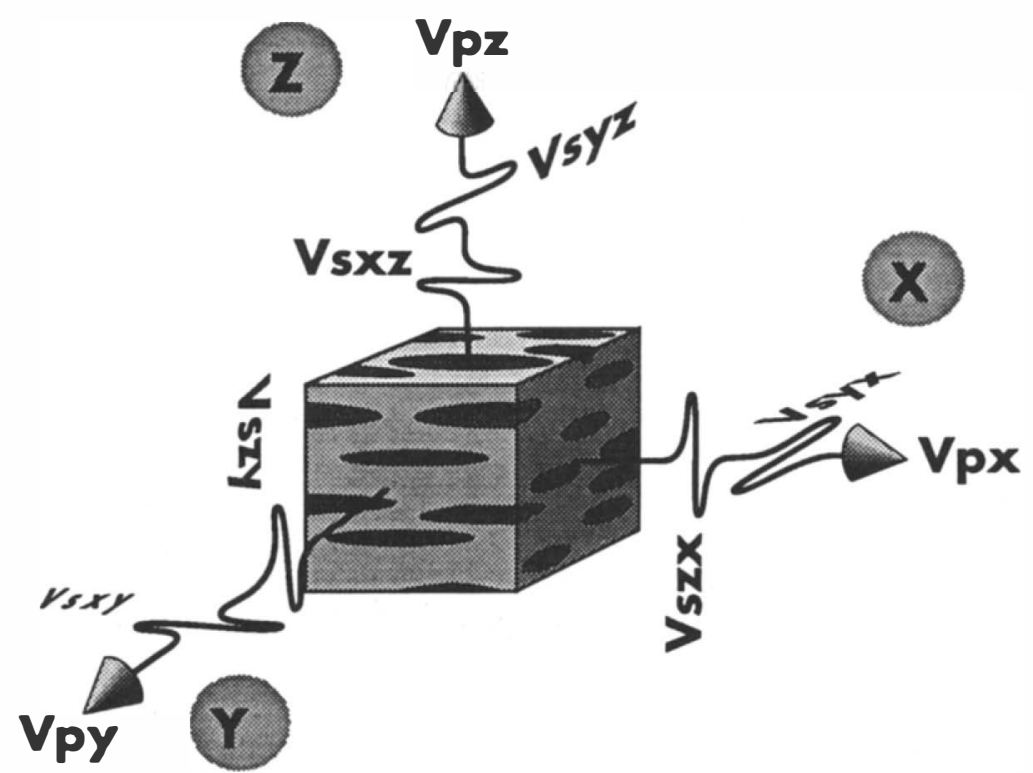

Fig. 1. Schematic diagram showing the orientations of $\mathrm{P}$ - and $\mathrm{S}$-wave velocity measurements in the structural reference frame ( $X$, $Y, Z$ ) on a cube-shaped specimen. For instance, $V_{\mathrm{p}_{X}}$ represents $V_{\mathrm{p}}$ measurements along the $X$ direction and $V_{\mathrm{s}_{X Y}}$ represents velocity measurements of a shear-wave polarized within the $X Y$ plane and propagating along the $Y$ direction. 
(Pyrénées, France) and in the Ivrea zone (northern Italy). Data from Seront et al. (1993) have been obtained on an Oklaoma anorthosite.

Table 1 summarizes birefringence values $\left(V_{\text {smax }}\right.$ $\left.-V_{\text {smin }}\right)$ in kilometres per second at $600 \mathrm{MPa}$ confining pressure and the percentage of birefringence anisotropy defined as $\left[\left(V_{\mathrm{smax}}-V_{\mathrm{smin}}\right) /\right.$ $\left.V_{\text {smean }}\right] 100$, with $V_{\text {smean }}=\left(V_{\text {smax }}+V_{\text {smin }}\right) / 2$. Birefringence may reach $1 \mathrm{~km} \mathrm{~s}^{-1}$ but typical birefringences range between 0.1 and $0.3 \mathrm{~km} \mathrm{~s}^{-1}$. Birefringence is often higher for propagation parallel to the $X$ - or $Y$-axes than to the $Z$-axis. Figure 2 shows the frequency histograms of the measured birefringence for each structural direction of the 28 samples. Distributions of values along the $X$ and $Y$ directions are very similar. The maximum number of measured anisotropies are lower than $4 \%$ for these two directions but the spectrum is very wide and about $50 \%$ of samples exhibit significant anisotropies (above 4\%). On the other hand, anisotropies measured along the $Z$ structural axis (Fig. 2, right) are systematically lower than $4 \%$ (and frequently less than $1 \%$, see Table 1), except for plagioclase-rich rocks. Similarly,

\section{TABLE 1}

Summary of the birefringence obtained by direct laboratory measurements

\begin{tabular}{|c|c|c|c|c|c|c|c|}
\hline Data origin & Sample & $\begin{array}{l}\| X \\
(\%)\end{array}$ & $\begin{array}{l}\| Y \\
(\%)\end{array}$ & $\begin{array}{l}\| Z \\
(\%)\end{array}$ & $\begin{array}{l}\| X \\
\left(\mathrm{~km} \mathrm{~s}^{-1}\right)\end{array}$ & $\begin{array}{l}\| Y \\
\left(\mathrm{~km} \mathrm{~s}^{-1}\right)\end{array}$ & $\begin{array}{l}\| Z \\
\left(\mathrm{~km} \mathrm{~s}^{-1}\right)\end{array}$ \\
\hline \multirow{10}{*}{$\begin{array}{l}\text { Christensen } \\
\text { (1966) }\end{array}$} & Garnet schist & 22.7 & 18.7 & 0 & 0.79 & 0.67 & 0 \\
\hline & Staurolite garnet schist & 33.1 & 27 & 0 & 1.17 & 0.95 & 0 \\
\hline & Kyanite schist 1 & 8.9 & 8.5 & 0 & 0.3 & 0.29 & 0 \\
\hline & Gneiss 2 & 5.7 & 4.6 & 0 & 0.2 & 0.16 & 0 \\
\hline & Gneiss 4 & 6 & 7.7 & 0 & 0.21 & 0.28 & 0 \\
\hline & Gneiss 5 & 7.5 & 6.3 & 0 & 0.27 & 0.22 & 0 \\
\hline & Gneiss 6 & 17.4 & 14.3 & 0 & 0.65 & 0.53 & 0 \\
\hline & $\begin{array}{l}\text { Felfdspathic micas } \\
\text { quartzite }\end{array}$ & 4 & 5.2 & 0 & 0.15 & 0.2 & 0 \\
\hline & Slate & 30 & 28.2 & 0 & 1.05 & 1 & 0 \\
\hline & Amphibolite 2 & 13.8 & 11.5 & 1.3 & 0.56 & 0.47 & 0.05 \\
\hline $\begin{array}{l}\text { Seront et al. } \\
\text { (1993) }\end{array}$ & Anorthosite & 8.8 & 9.4 & 11.3 & 0.32 & 0.34 & 0.41 \\
\hline \multirow{4}{*}{$\begin{array}{l}\text { Kern and Wenk } \\
\text { (1990) }\end{array}$} & Mylonite PC 82 & 5.3 & - & 0.6 & 0.19 & - & 0.021 \\
\hline & Mylonite PC 96 & 8.2 & - & 0.7 & 0.299 & - & 0.026 \\
\hline & Phyllonite PC 95 & 9.1 & - & 0.8 & 0.329 & - & 0.027 \\
\hline & Phyllonite PC 92 & 12.1 & - & 0.8 & 0.432 & - & 0.027 \\
\hline \multirow[t]{5}{*}{$\begin{array}{l}\text { Barruol et al. } \\
\text { (1992) }\end{array}$} & $\begin{array}{l}\text { Felspath garnet } \\
\text { granulite SB122 }\end{array}$ & 1.4 & 3 & 0.1 & 0.056 & 0.111 & 0.004 \\
\hline & Phyllonite SB2a & 27.6 & 28 & 0.3 & 0.99 & 1.018 & 0.01 \\
\hline & Gneiss SB83 & 0.1 & 3 & 2.4 & 0.003 & 0.111 & 0.088 \\
\hline & Mylonite SB89 & 9.6 & 10.9 & 0.2 & 0.349 & 0.399 & 0.006 \\
\hline & Quartzite SB114a & 8.1 & 5.4 & 0.7 & 0.323 & 0.217 & 0.029 \\
\hline \multirow{8}{*}{$\begin{array}{l}\text { Barruol and Kern } \\
\text { (1993) }\end{array}$} & Amphibolite 12 & 3 & 6.3 & 3.3 & 0.12 & 0.25 & 0.128 \\
\hline & Stronalite 19 & 0.6 & 4.3 & 0 & 0.025 & 0.172 & 0 \\
\hline & Felsic amphibolite 33 & 10 & 9.9 & 0.8 & 0.401 & 0.393 & 0.032 \\
\hline & Gabbro 46 & 1.2 & 0.6 & 1.5 & 0.047 & 0.023 & 0.057 \\
\hline & Granulitic gabbro 48 & 0.1 & 0.2 & 0.4 & 0.003 & 0.009 & 0.016 \\
\hline & Pyrox. plagio. amph. 53b & 0 & 1.8 & 3 & 0.001 & 0.073 & 0.123 \\
\hline & Quartzitic stronalite $54 \mathrm{a}$ & 0.7 & 1.4 & 0.4 & 0.028 & 0.06 & 0.015 \\
\hline & Pyriclasite $77 \mathrm{~b}$ & 2.3 & 1.8 & 0.5 & 0.093 & 0.074 & 0.02 \\
\hline
\end{tabular}

Reported data have been obtained at $600 \mathrm{MPa}$ confining pressure and at room temperature. The birefringence values (km $\left.\mathrm{s}^{-1}\right)$ and the birefringence anisotropy $(\%)$ for each sample, as defined in the text, are presented. 
TABLE 2

Modal composition of the samples for which direct birefringence measurements have been performed

\begin{tabular}{|c|c|c|c|c|c|c|}
\hline Sample & Quartz & Micro. & Biotite & Plagio. & Amphib. & Others \\
\hline Garnet schist & 29.0 & 0.0 & 30.0 & 35.0 & 0.0 & 5.0 al., $1.0 \mathrm{ma}$. \\
\hline Staurolite garnet schist & 44.0 & 0.0 & 23.0 & 13.0 & & $13.0 \mathrm{mu} ., 2.0 \mathrm{al}$. \\
\hline Kyanite schist 1 & 8.0 & & 14.0 & 23.0 & & $23.0 \mathrm{mu} ., 2.0 \mathrm{al}$. \\
\hline Gneiss2 & 22.1 & 38.7 & 5.3 & 22.7 & & $1.4 \mathrm{mu}$ \\
\hline Gneiss4 & 19.5 & 0.4 & 16.5 & 45.6 & 17.4 & $0.1 \mathrm{mu} ., 0.3 \mathrm{sp} ., 0.2 \mathrm{ma}$. \\
\hline Gneiss5 & 8.9 & & 18.3 & 50.0 & 21.5 & $1.3 \mathrm{cl}$ \\
\hline Gneiss6 & 39.4 & & 20.8 & 31.9 & & $4.1 \mathrm{mu} ., 2.8$ al., $1.0 \mathrm{si}$. \\
\hline $\begin{array}{l}\text { Felspathic mica quartzite } \\
\text { Slate }\end{array}$ & 68.9 & & 10.1 & 20.2 & & $0.5 \mathrm{mu} ., 0.2$ ap., 0.1 al. \\
\hline Anorthosite & & & & 90.0 & & $10.0 \mathrm{ol}$. \\
\hline Mylonite PC82 & 24.0 & 14.0 & 9.0 & 49.0 & & \\
\hline Mylonite PC96 & 26.0 & 13.0 & 11.0 & 50.0 & & \\
\hline Mylonite PC95 & 26.0 & 7.0 & 9.0 & 55.0 & & \\
\hline Mylonite PC92 & 25.0 & 7.0 & 9.0 & 55.0 & & \\
\hline Felsic acid gran. SB122b & 45.0 & 10.0 & 8.0 & 12.0 & & 15.0 gar., 5.0 si., 5.0 pyrox \\
\hline PhylloniteSB2a & & & 100 & & & \\
\hline GneissSB83 & 35.0 & 28.0 & 15.0 & 18.0 & & 2.0 gar., 2.0 si., \\
\hline MyloniteSB89b & 30.0 & 15.0 & 45.0 & 10.0 & & \\
\hline QuartziteSB114a & 100.0 & & & & & \\
\hline Amphibolite 12 & 4.0 & & & 35.0 & 59.0 & $1.0 \mathrm{ox}$. \\
\hline Stronalite 19 & 55.0 & 10.3 & & & & 8 sill., 25.2 gar., 1.5 ox. \\
\hline Felsic amphibolite 33 & & & & 35.8 & 54.2 & 8 pyrox., 2.0 ox. \\
\hline Stronalite 46 & 35 & & & & & 55 feldsp., 10 pyrox. \\
\hline Granulitic gabbro 48 & & & & 58.0 & 19.0 horn. & 23.0 pyrox. \\
\hline Pyroxenite plagio. 53b & & & & 25.4 & & 68.5 pyrox., 4.5 spi., 1.6 ox. \\
\hline Quartzitic stronalite 54a & 48.4 & 37.0 & & & & 13.8 pyrox., $0.8 \mathrm{ox}$. \\
\hline Pyriclasite 77b & & & & 47.0 & & 52 pyrox., 1 ox. \\
\hline
\end{tabular}

al, almandite; ma, magnetite; mu, muscovite; sp, sphene; cl, clinozoisite; si, sillimanite; ap, apatite; ol, olivine; gar, garnet; ox, oxydex; spi, spinel; pyrox, pyroxene; feldsp, feldspar.
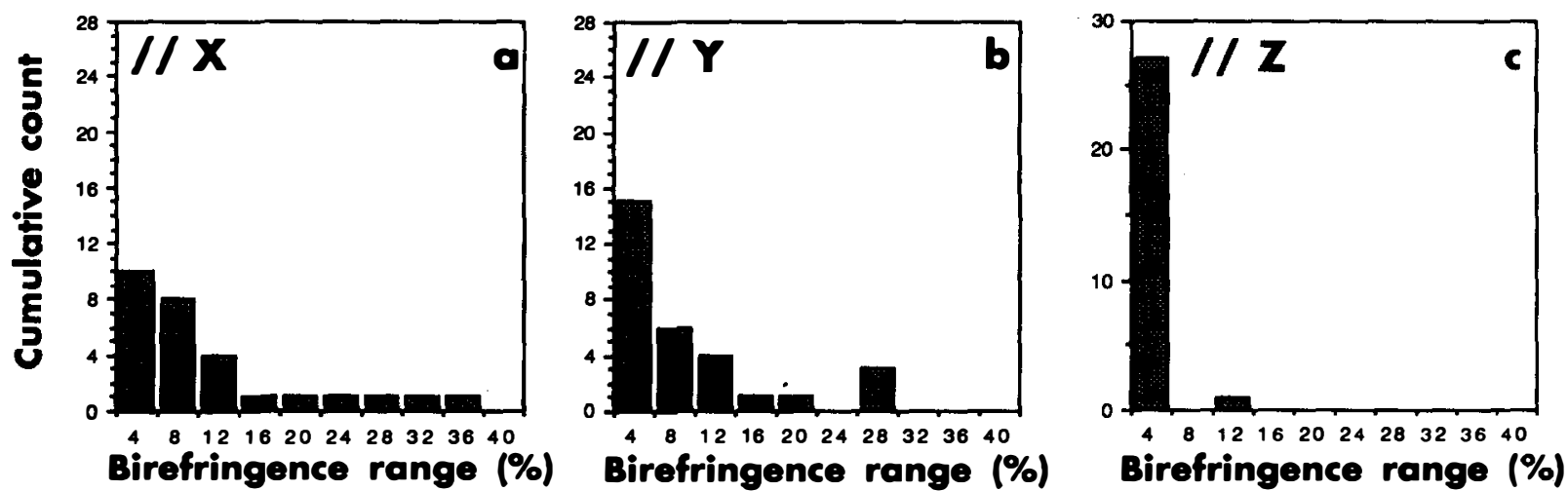

Fig. 2. Summary diagrams showing the frequency of measured birefringence anisotropies (as defined in the text). Each diagram corresponds to a structural direction (see Table 1). Birefringence anisotropy measured normal to the foliation (along the $Z$ structural axis) is systematically lower than $4 \%$, and in $80 \%$ of the samples it is lower than $1 \%$. On the other hand birefringence measured along the $X$ and $Y$ directions displays a very similar pattern: the maximum number of anisotropies is lower than $4 \%$ but about $50 \%$ of the samples exhibit birefringence anisotropies higher than $4 \%$. The total number of measurements is 28 . 
average birefringence anisotropies (Fig. 3) clearly show high values within the foliation plane $(9 \%$ and $8 \%$, respectively, along the $X$ and $Y$ directions) and very low values for waves propagating normal to the foliation plane (about 1\%).

Laboratory measurements of shear-wave splitting have been performed at confining pressures up to $600 \mathrm{MPa}$ on 45 drilled rocks sampled in the KTB hole (Kern et al., 1991) (Fig. 4). In the rock samples (biotite gneisses, amphibolites, metagabbros) the shear-wave splitting is systematically higher within the foliation plane than normal to it.

In summary laboratory S-wave birefringence measurements performed on gneissic or amphibolitic rocks show strong splitting within the foliation plane whereas splitting normal to the foliation is very small.

The main factor controlling the shear-wave splitting at high confining pressure (above 200 $\mathrm{MPa}$ ) has been interpreted as being modal composition and mineral lattice preferred orientation of the rocks (particularly of phyllosilicates). At low confining pressure, the main factor controlling velocity variations is microcracks. Kern (1990) clearly shows that microcracks close at about 200 $\mathrm{MPa}$ confining pressure. Above $200 \mathrm{MPa}$, the intrinsic mineral seismic properties become domi-

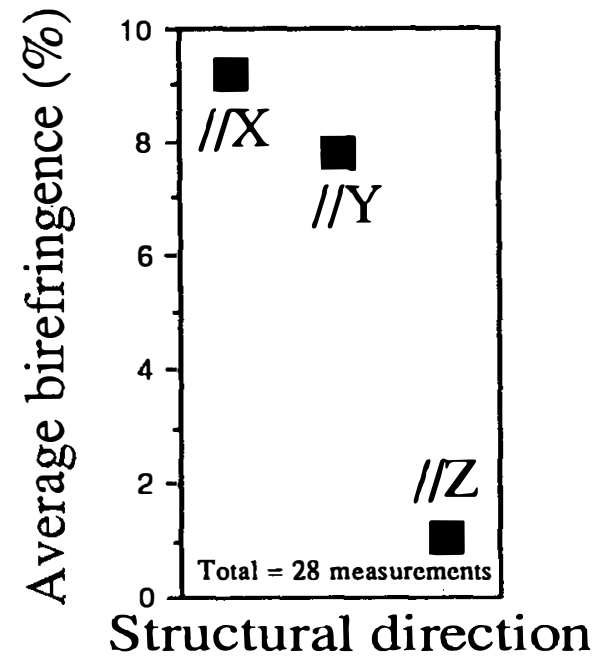

Fig. 3. Average birefringence anisotropies (as defined in the text) for the 28 measurements for the three structural directions.

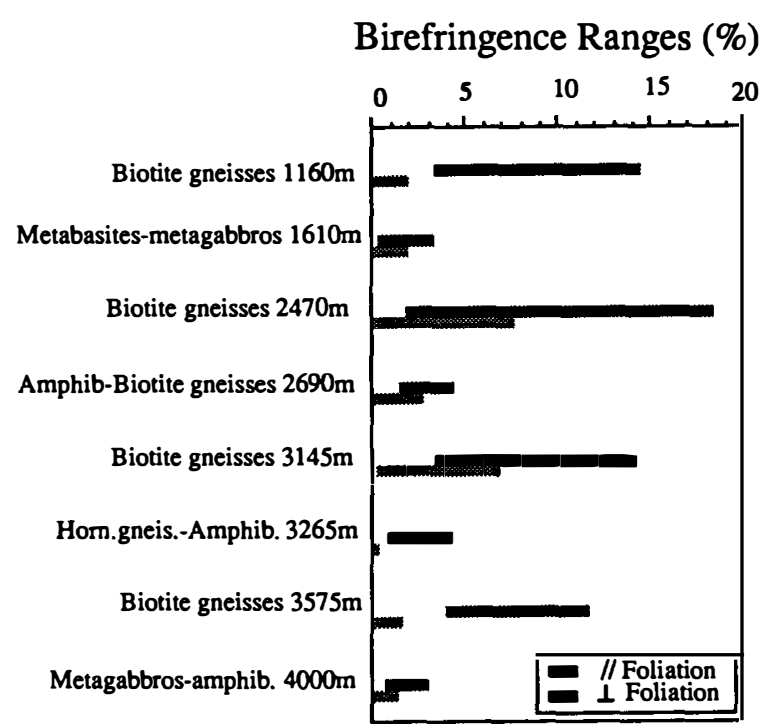

Fig. 4. Birefringence ranges measured on about 45 samples (Kern, 1991), drilled in the KTB hole. The vertical axis represents the schematic lithologic units and the corresponding depth ranges. Birefringences have been measured in directions normal to the foliation (grey) or for S-waves propagating along directions contained within the foliation plane (black). Birefringence is systematically lower when measured normal to the foliation.

nant. Variations of seismic velocities are mainly controlled by their pressure and temperature derivatives. Biotite and amphibole have often been described as playing a major role in anisotropy for P- and S-waves (e.g. Fountain et al., 1984; McDonough and Fountain, 1988; Kern and Wenk, 1990; Barruol et al., 1991).

\section{Calculations of SWS from petrofabric data}

Three-dimensional (3-D) distribution of seismic velocities $\left(V_{\mathrm{p}}, V_{\mathrm{s}}\right.$, shear-wave birefringence) in an anisotropic polymineralic rock is calculated from single crystal densities and elastic stiffness coefficients, LPO and volume fraction of each mineral species. Using an interactive program (Mainprice, 1990), the procedure for the calculation of seismic phase velocities uses the Christoffel equation and has been described in detail by Crosson and Lin (1971) and Peselnick et al. (1974). 


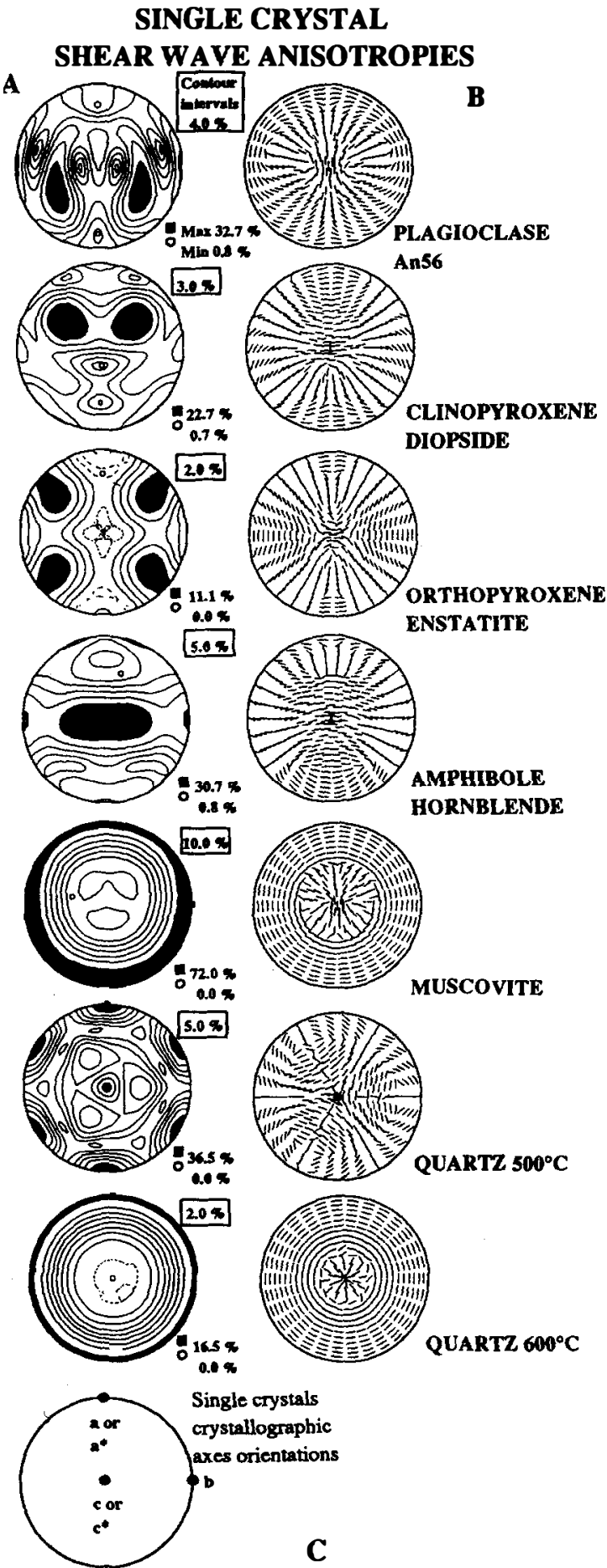

This kind of calculation provides the opportunity to understand the three steps of the calculation and hence the final results: (1) the seismic anisotropy of the single crystal; (2) the seismic properties of each mineral phase; (3) the influence of each mineral's bulk percentage on the polymineralic aggregate anisotropy. This allows us to obtain 3-D patterns of anisotropy in direct relationship to the rock structure (foliation and lineation).

\subsection{Single crystals $S$-wave properties}

Figure 5 shows the 3-D single crystal S-wave anisotropies. The two shear-wave velocities $\left(V_{\mathrm{s} 1}\right.$ and $\left.V_{\mathrm{s} 2}, V_{\mathrm{s} 1}>V_{\mathrm{s} 2}\right)$ and the orientations of their polarization planes are determined for each propagation direction. Contour diagrams of birefringence anisotropy (Fig. 5(A)), and orientation of the fast shear-wave $V_{\mathrm{s} 1}$ (Fig. 5(B)) are shown in equal area projection in the crystallographic reference frame (Fig. 5(C)). The single crystal birefringence anisotropies are in the range from $10 \%$ (enstatite) up to $70 \%$ (muscovite). Orientation of maximum birefringence anisotropy value is shown by a black square, the minimum by a white circle. Note the contour intervals are not the same for every mineral.

The plagioclase crystal is triclinic but the stiffness coefficients have been calculated using monoclinic symmetry by Aleksandrov et al. (1974).

Fig. 5. Single crystal shear-wave properties. The birefringence anisotropies (as defined in the text) (A), and the polarization plane orientations (B) are shown in equal area projection in the crystallographic reference frame. The maximum birefringence is marked by a filled square and the minimum by an open circle. Note that the contour intervals are not the same for every single crystal. For each propagation direction, the little arc segment represents the orientation of the polarization plane of the fast split shear-wave and is a part of a great circle. The $V_{\mathrm{s} 2}$ polarization plane orientation is at every point perpendicular to the $V_{\mathrm{sl}}$ orientation. The equal area projection is done in a crystallographic reference frame (C). North represents the $a$ crystallographic axis (or [100]) or $a^{*}$ for monoclinic and triclinic crystals (the normal to the (100) crystallographic plane). The east direction corresponds to the $b$ (or [010]) crystallographic direction. 
LATTICE PREFERRED ORIENTATIONS
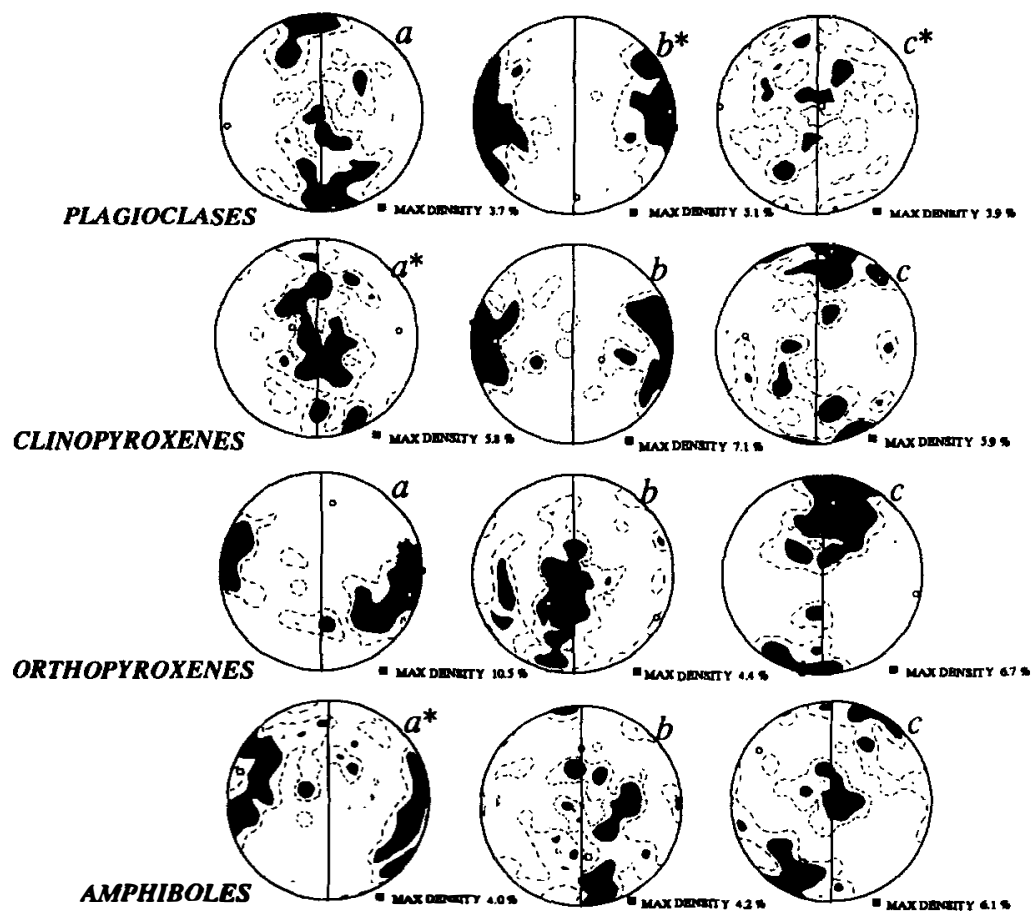

BIOTITE

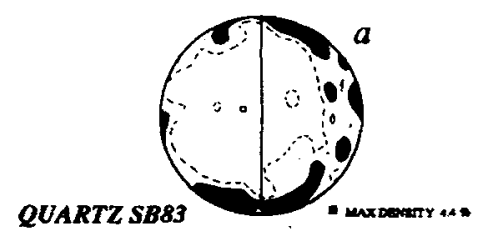

Vs ANISOTROPY VsI ORIENTATION
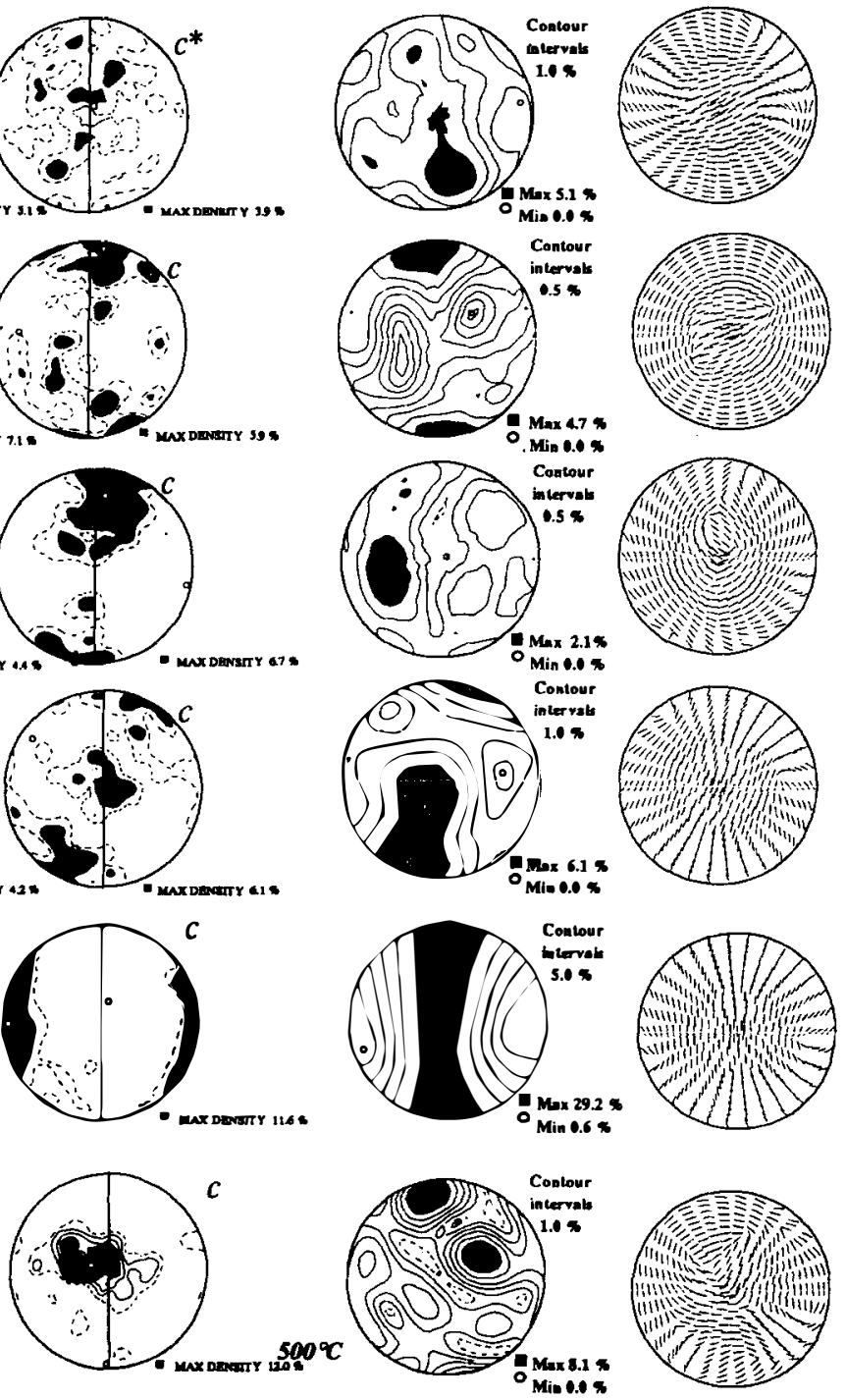
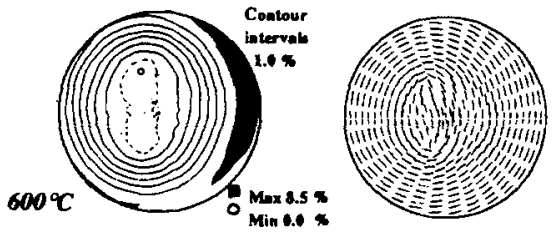

Fig. 6. Typical LPO of the main crystallographic axes of crustal mineral phases selected to model S-wave properties of synthetic crustal rocks. The projections are in the structural reference frame: foliation is north-south and lineation is north-south. Maximum density of crystallographic axes is marked by a filled square (left). The 3-D variations of the birefringence anisotropy of the ideal aggregate composed of $\mathbf{1 0 0 \%}$ of the given mineral with the measured LPO and the fast split shear-wave polarization plane orientations are shown on the right. For more details see text. 
This explains the only monoclinic symmetry of the diagrams. The anisotropy pattern shows numerous maxima and minima, with complex angular relations with the crystallographic axes. Only the $a^{*}$ direction is close to the lowest anisotropy value.

Clinopyroxene (Cpx) stiffness coefficients were determined by Aleksandrov and Ryzhova (1961) on diopside. The seismic properties clearly exhibit the monoclinic symmetries. There is no direct relation between the orientations of maximum anisotropies and the Cpx principal crystallographic axes.

The hornblende stiffness coefficients (Aleksandrov and Ryzhova, 1961) have been used to characterize amphibole seismic properties. The minimum birefringence orientation is close to the $a$ crystallographic axis but to the $c$-axis corresponds the maximum value of $\mathrm{S}$-wave anisotropy $(30 \%)$. Furthermore, the plane containing the $b$ and $c$ crystallographic directions forms a girdle of high anisotropies ( $>20 \%$ ). For these highly birefringent directions, the fast shear-wave $\left(V_{\mathrm{s} 1}\right)$ is systematically polarized parallel to the (100) crystallographic plane.

Orthopyroxene (Opx) stiffness coefficients were measured on enstatite (Weidner et al., 1978). The seismic properties show the two-fold symmetry axes parallel to the $a-, b$ - and $c$-axes. The directions of maximum anisotropy do not correspond to principal crystallographic axes. The plane containing the $a$ - and $c$-axes forms a girdle of very small anisotropies $(<2 \%)$. Opx is the least anisotropic of all minerals considered here (maximum anisotropy 11\%).

For biotite we used constants measured by Vaughan and Guggenheim (1986) on muscovite which shows very close similarity with biotite crystal structure and elastic properties. These data are indeed more recent and more reliable than those of Aleksandrov and Ryzhova (1961) for the biotite single crystal. Biotite, although monoclinic, can be considered as hexagonal to a good approximation for its elastic constants. Muscovite is strongly birefringent (anisotropy up to 70\%) in directions normal to the $c$ or [001] direction due to the phyllosilicate sheets, or (001) plane. On the other hand, directions of propagation close to the $c$-axis are almost isotropic. For, S-waves propagating at an angle of less than $45^{\circ}$ to the cleavage plane, the fast shear-waves $\left(V_{\mathrm{s} 1}\right)$ are always polarized parallel to the cleavage. Seismic waves have the highest velocities when their polarization and propagation directions are parallel to the cleavage, which corresponds to the plane of highest atomic packing. Note that biotite seismic properties can be completely described with only the $c$-axis orientation because of its transverse isotropy.

Elastic stiffness constants of $\alpha$ - and $\beta$-quartz single crystal near the phase transition (510 and $600^{\circ} \mathrm{C}$ ) were reported by Zubov and Firsova (1962). Quartz S-wave properties in the $\alpha$ field (below $573^{\circ} \mathrm{C}$ at room pressure) reflect its trigonal symmetry with highest anisotropies parallel to the $a$-axis and the $c$ crystallographic direction corresponding to a three-fold axis. In the $\beta$-field, quartz is transversely isotropic, the $c$-axis is the symmetry axis and the minimum of anisotropy (Mainprice et al., 1990). The $\beta$ quartz phase has considerably lower S-wave birefringence (16\%) than $\alpha$-quartz (36\%).

\subsection{S-wave properties of monocrystalline aggre- gates}

To derive realistic simple models of seismic properties of lower to middle crustal rocks, representative LPOs and compositions of natural rocks have been selected. For LPO two main criteria have been used: (1) the general symmetry and the statistical orientation of crystallographic axes must be frequently reported in the literature; (2) the fabric intensity must be representative of common rocks-very strong fabrics (e.g. mylonites) which are unlikely to be representative on the kilometre scale have been discarded.

Selected LPOs (Fig. 6) were mainly measured in Ivrea Zone (northern Italy) samples (Barruol and Mainprice, 1993), except for quartz fabrics which have been measured in a gneiss sampled in the Saint Barthélémy Massif (northern Pyrénées, France) (Barruol et al., 1991). Lattice preferred orientations were measured using an optical microscope equipped with a universal stage, except for quartz for which a scanning electron micro- 
scope (SEM) was used. Quartz is optically uniaxial, hence only the $c$-axis orientation can be obtained using an optical microscope. This is not enough to calculate the seismic properties, which also depend on the $a$ - and $m$-axes orientations, at least for the temperature range below the $\alpha-\beta$ quartz transition (about $573^{\circ} \mathrm{C}$ ). The SEM was used to investigate quartz crystallographic orientation using the channelling method and indexing Selected Area Electron Channelling Patterns (SAECP) (Lloyd and Hall, 1981; Lloyd et al., 1987). This powerful method allows measurements of the complete crystallographic orientation of individual grains. Crystallographic orientation determinations of monoclinic and triclinic minerals such as amphibole, pyroxene, plagioclase have been greatly simplified using microcomputers programs (Benn and Mainprice, 1989).

From the preferred orientation of the three principal crystallographic axes for each mineral (Fig. 6, left) the birefringence anisotropies and the orientations of $V_{\mathrm{s}_{1}}$ polarization planes of an ideal aggregate composed of $100 \%$ of a given mineral with the considered LPO was computed (Fig. 6, right).

Plagioclase, orthopyroxene and clinopyroxene fabrics were measured in a gabbro sampled in the lowermost levels of the Ivrea Zone, in the Val Sesia section (Barruol and Mainprice, 1993), a few hundreds of meters east of the Balmuccia peridotites. This gabbro has been deformed under granulite facies conditions and the mineral preferred orientations probably result from ductile deformation.

Plagioclase exhibits a fabric typical of granulite facies metamorphic conditions (Ji et al., 1988; Siegesmund and Kruhl, 1991) that suggest activation of the (010)[100] slip system. Although plagioclase fabric is relatively simple, the corresponding S-wave anisotropy displays a complex pattern with numerous subsidiary maxima and minima, clearly due to the complexity of the single crystal properties. There is no clear relationship between the main structural axes and the maximum birefringence. The maximum birefringence anisotropy is also relatively low (5.1\%) compared with the single crystal $(32 \%)$ due to the diluting effect of the petrofabric. The polariza- tion plane orientations (PPO) have a complex pattern.

Cpx (diopside/hedenbergite), seems to have been less ductile than plagioclase (some grains are fractured or kinked) but most grains are elongated and the crystallographic fabric shows a concentration of $b$-axes close to the foliation pole and $c$-axes close to the lineation. Such fabrics have been previously described in ultramafic rocks (Boudier, 1978; Mercier, 1985). The ideal Cpx aggregate has a relatively complex birefringence pattern, with low anisotropy values (maximum 4.7\%). The maximum birefringence anisotropy is close to the $X$ structural axis (lineation). The PPO are systematically normal to the foliation plane.

Opx (enstatite) exhibits a classic LPO with the $a$-axes close to the pole of the foliation and the $c$-axes forming a maximum close to the lineation (e.g. Mercier, 1985). An aggregate ideally composed of $100 \%$ Opx with this fabric would display a low anisotropy (maximum birefringence anisotropy $2 \%$ ). The minimum birefringence corresponds to the maximum $c$-axis concentration. The maximum is roughly between the $b$ and $a$-axes. Furthermore, PPO for waves propagating in the principal structural directions $(X, Y$ or $Z)$ are always oblique to the main structural planes.

Amphibole (hornblende) petrofabric has been measured in a diorite, sampled in the upper part of a gabbro to diorite magmatic intrusion, at about $8 \mathrm{~km}$ east of the Balmuccia massif in the Val Mastallone. The rock is composed of plagioclase $(65 \%)$, hornblende $(10 \%)$, enstatite $(7 \%)$, diopside $(8 \%)$ and biotite $(10 \%)$ and is totally free of plastic deformation microstructures. Plagioclase grains show typical parallel-sided twins and elongated grains define a weak magmatic foliation. Hornblende $a$-axes are statistically oriented close to the pole of the foliation whereas $b$ and $c$-axes form a discontinuous girdle within the foliation plane (Fig. 6). Amphibole $c$-axes nevertheless show a maximum concentration close to the lineation. This kind of magmatic fabric is similar to those measured in metamorphic rocks (e.g. Siegesmund et al., 1989). The ideal aggregate computed from this fabric has a relatively high anisotropy (maximum 6.1\%) despite the 
complex fabric with the numerous submaxima. High birefringence values define a girdle roughly parallel to the foliation plane with a maximum close to the lineation (due to the $c$-axes concentration). Despite the complex fabric, the amphibole aggregate polarization plane pattern is simple (Fig. 6). S-waves propagating parallel to the lineation are polarized parallel to the foliation and more generally, waves propagating parallel to the foliation plane generate a fast shear-wave polarized parallel to it. This aggregate shows clear relationships between the seismic velocities (and particularly the birefringence), the PPO and the structural fabric of the rock (particularly with the foliation).

Biotite LPO was measured in a kinzigite from the upper part of the Val Sesia section, about 10 $\mathrm{km}$ east from the Balmuccia Massif. This rock consists of feldspar (55\%), quartz $(20 \%)$, biotite $(20 \%)$ and garnet $(5 \%)$. The foliation is defined by the orientation of biotite crystals. Because the elastic constants of biotite have been calculated as pseudohexagonal, only the measurement of the $c$-axis orientation is required to calculate the elastic constants of a polycrystalline aggregate. The $c$-axis has been determined as normal to the cleavage plane and the $a$ and $b$-crystallographic orientations have been randomly generated in the plane normal to the $c$-axis. In this sample, $c$-axes are clearly grouped in a maximum normal to the foliation (Fig. 6). Biotite flakes are strongly anisometric and develop strong preferred orientations with their cleavage planes parallel to the foliation. An aggregate composed of $100 \%$ biotite with this fabric exhibits a girdle of very high birefringence anisotropy (about 30\%) within the foliation plane. The fast shear-wave PPO also displays a very simple pattern (Fig. 6); propagation directions contained within or close to the foliation are strongly birefringent and the fast shear-wave is polarized parallel to the foliation. Propagation directions at high angle to the foliation plane (close to the $Z$-axis) are weakly anisotropic (less than 5\%). Biotite is clearly an important mineralogic phase for S-wave splitting studies in crustal rocks due to: (1) the strong intrinsic anisotropy of biotite single crystal $(70 \%$ birefringence anisotropy); (2) the strong and sim- ple preferred orientation; (3) the direct relationship between structural reference frame, the orientations of maximum birefringence and the orientations of the polarization planes of the fast shear-wave (parallel to the phyllosilicate sheets, i.e. parallel to the foliation).

Quartz fabric was measured in a gneiss from the Saint Barthélémy Massif (Northern Pyrénées, France), deformed in the amphibolite facies. The tectonic context has been described by Saint Blanquat (1990) and the microstructure and composition of this rock have been already described by Barruol et al. (1992). The microstructure is typical of rocks from the middle crust: ribbon quartz grains, feldspars with brittle features, some recrystallization and biotite with strong preferred orientation. The 6 measured quartz LPO is typical of the middle to lower crust (e.g. Bouchez, 1977; Schmid and Casey, 1986): the $c$-axes form a maximum close to the $Y$ structural axis (normal to the lineation within the foliation plane), and the $a$-axes are concentrated near the lineation (Fig. 6). Despite this very simple LPO, an ideal aggregate of $\alpha$-quartz exhibits a very complex birefringence pattern with two maxima with different orientations. A strong maximum of birefringence anisotropy $(8.1 \%)$ occurs parallel to the lineation and a second at about $45^{\circ}$ of the three structural axes (Fig. 6). The distribution is also characterized by numerous orientations with low birefringence and by strong gradients between high and low birefringence values. The fast shear-wave PPO display strong spatial variations.

The $\alpha-\beta$ phase transition completely changes the elastic properties of quartz from trigonal in the $\alpha$ field to transversely isotropic around the $c$-axis in the $\beta$ field. This axis corresponds to the orientation of the minimum birefringence. Because $c$-axes are orientated parallel to the $Y$ structural direction, the quartz aggregate with this LPO shows a minimum anisotropy normal to the lineation within the foliation plane (i.e. close to the $Y$ structural direction) and high birefringence values in the $X Z$ plane. For S-waves propagating in a direction close to the $Z$-axis, the anisotropy is strong (about $8 \%$ ) and the fast shear-wave PPO is parallel to the lineation. Note that the maximum birefringence is greater in $\beta$ - 
quartz aggregate (8.5\%) than $\alpha$-quartz (8.1\%) due to the transversely isotropic seismic properties of $\beta$-quartz compared with trigonal $\alpha$-quartz.

\subsection{Modelling 3-D birefringence of synthetic crustal rocks}

Using typical LPO of the main crustal constitutive mineralogic phases, described previously, we generate elastic properties of rocks with realistic modal compositions. By 'synthetic' we mean that the rock consists of minerals with LPO measured in different samples. The elastic properties of each rock result from the combination of the elastic stiffness matrix of each mineral phase, calculated from its LPO, in the modal proportions of the rock and its density. Various kinds of lithologies representing large crustal volumes (at least $1 \mathrm{~km}^{3}$ ) have been modelled: a gabbro, an anorthosite and an amphibolite representing mafic rocks and three kinds of gneiss and a schist to represent the felsic crust. in most cases the LPO has been used to compute the elastic properties of the component mineral. In a few cases the isotropic equivalents, using the Voigt average, have been used. For example, it was assumed that plagioclase and $\mathrm{K}$-feldspars in the middle crust do not develop LPO as they do at deeper levels or higher metamorphic grades (e.g. Barruol et al., 1992); consequently, they have been considered as randomly oriented inducing isotropic elastic properties.

The shear-wave splitting properties have been computed for 10 synthetic rocks. The 3-D varia-

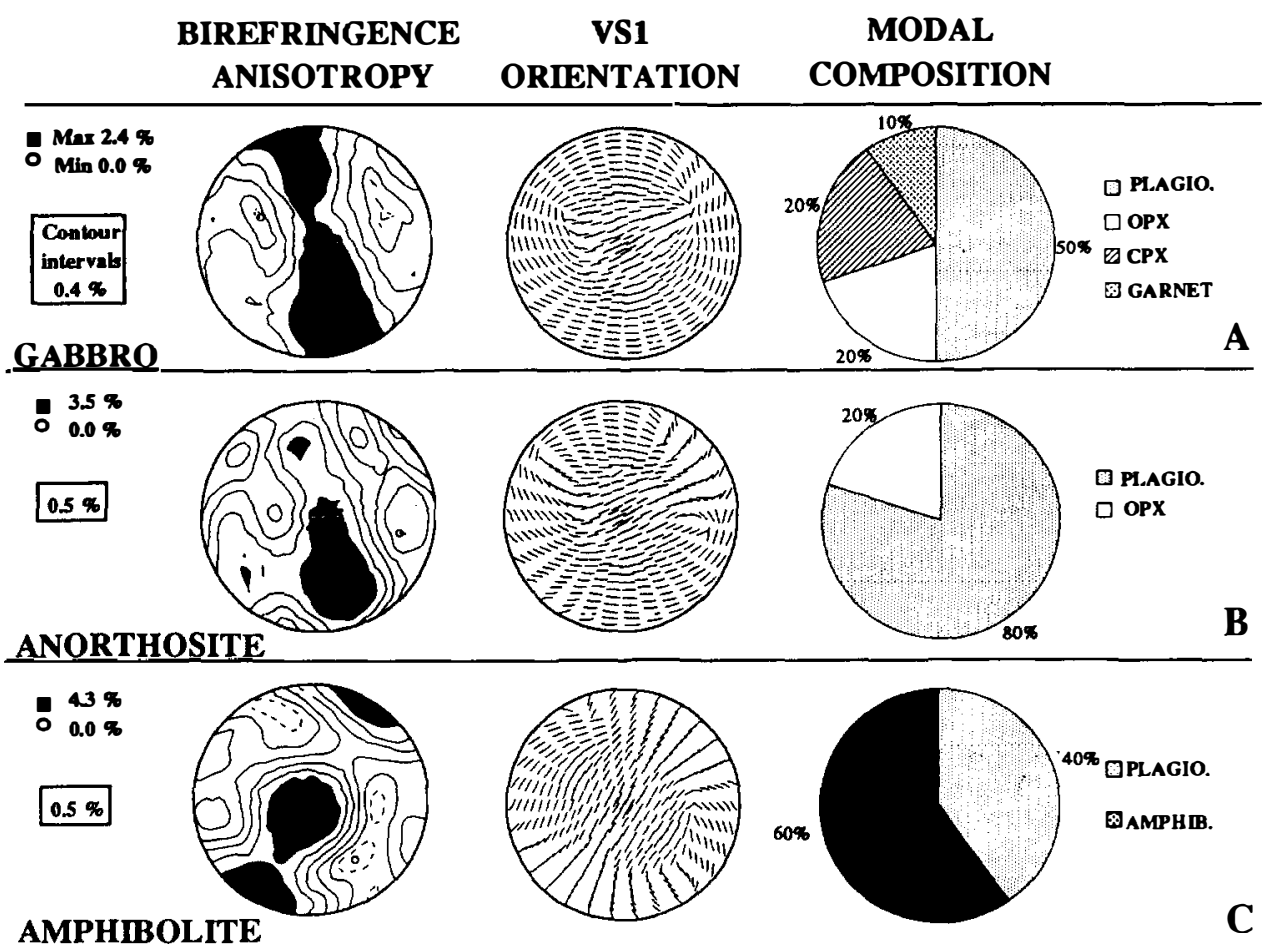

Fig. 7. Three-dimensional variations of the shear-wave properties of 10 synthetic aggregates. We have investigated various kinds of typical lithologies, from mafic (A), (B) and (C) to felsic compositions (D)-(J). For each synthetic crustal rock, the calculated birefringence anisotropies (left) and the orientations of the polarization planes of the fast split shear waves (middle) are shown in equal area projection, in the structural reference frame (foliation north-south and lineation north-south). The modal composition (on the right) is presented in a pie diagram. Mineralogic phases having the '.iso' name extension were considered as isotropic. Seismic properties of quartz-bearing rocks were determined above and below the $\alpha-\beta$ phase transition, at $600^{\circ} \mathrm{C}$ and $500^{\circ} \mathrm{C}$, respectively. 

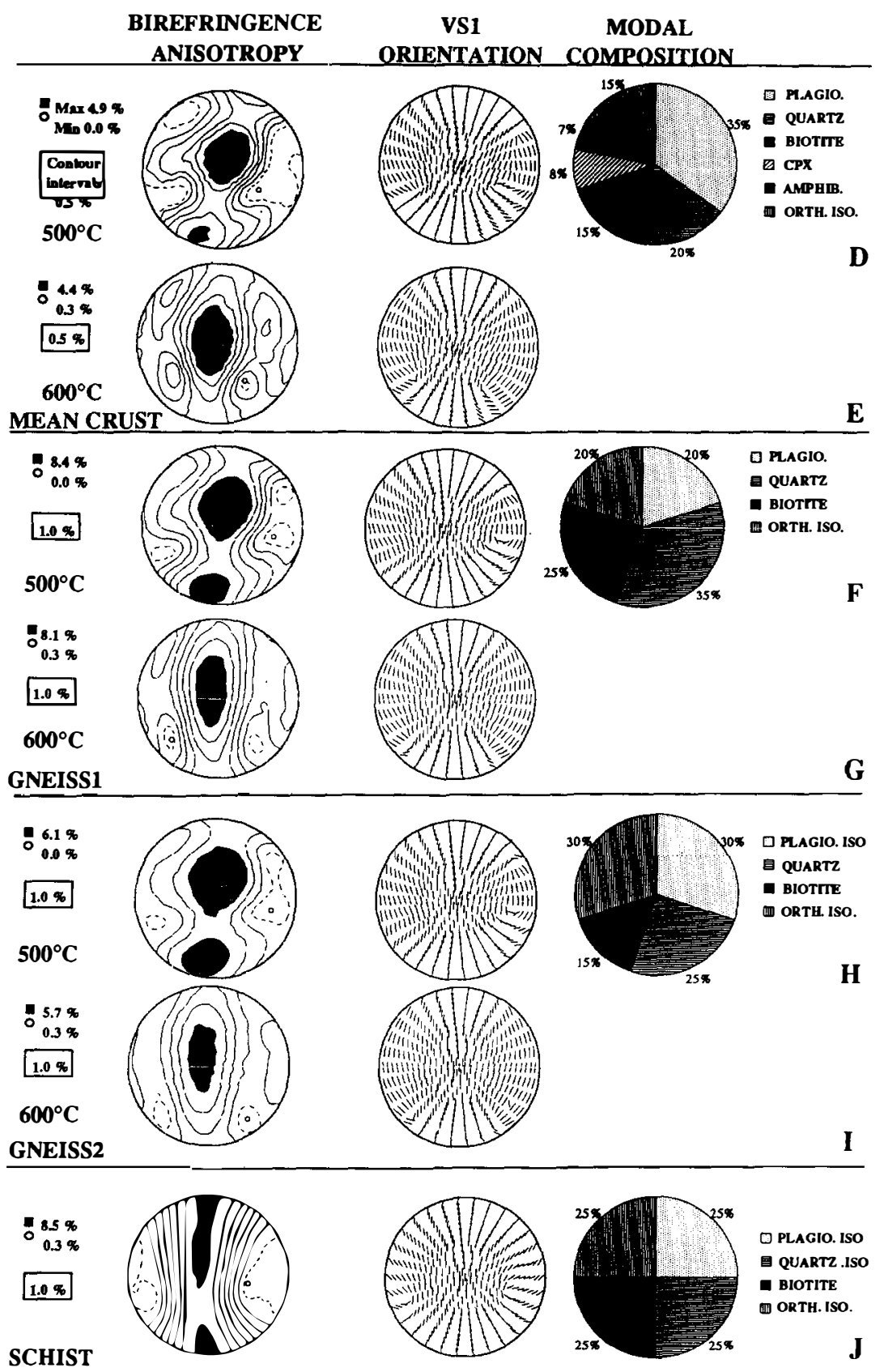

Fig. 7 (continued).

tions of the birefringence anisotropy (left), and the fast shear-wave polarization plane orientations (middle) are presented in Fig. 7, the corresponding modal composition is shown on the right. For more details about this figure, see the figure caption. From these calculations we can discuss: (1) the influence of modal composition, (2) the influence of the LPO (which is responsible 
for anisotropic properties) vs. the isotropic cases; (3) the effect of the temperature on the seismic properties of quartz-rich rocks $(\alpha-\beta)$ quartz transition).

Despite the fact that plagioclase represents a high volume fraction in the two mafic rocks $(50 \%$ and $80 \%$ for the gabbro and the anorthosite, respectively), their maximum birefringence anisotropy is relatively low $(2.4 \%$ and $3.5 \%$ ) (see Fig. 7(A)). Plagioclase LPO alone does not generate strong shear-wave anisotropies (maximum $5.1 \%)$. The amphibolite is more birefringent (maximum anisotropy $4.3 \%$ ).

Results from the gabbro illustrate the combined effect of plagioclase and Cpx (Fig. 7(A)). The plagioclase fabric generates a discontinuous zone of high birefringence values within the foliation plane and Cpx LPO results in high values close to the lineation. The bulk 3-D birefringence pattern displays a continuous girdle of high values roughly parallel to the foliation. Opx does not generate a significant effect, because of its very low anisotropy. Fast shear-wave PPO for plagioclase and Cpx fabrics are very similar and the resulting PPO for the whole aggregate has the same trend as in both mineralogical components. For S-waves propagating parallel to the foliation plane (directions of high birefringence), the fast $\mathrm{S}$-wave. splits with variable orientations. The absence of simple and homogeneous PPO trends enhances the difficulty in extracting structural information (i.e. orientation of the structure) using $\mathrm{S}$-wave delay time and polarization orientations.

The anorthosite (Fig. 7(B)) birefringence pattern is much more complex. The zones of high birefringence values are less continuous than for the gabbro and have no simple orientations relative to the structural reference frame, exactly like the plagioclase LPO which represents $80 \%$ of the rock. Highest birefringence is in the direction between $X$ and $Y$ in the foliation plane. The fast shear-waves' PPO are similar to those of the gabbro sample and the plagioclase single crystal.

The birefringence pattern and the fast shearwave PPO of the amphibolite (Fig. 7(C)) are the most simple from the three mafic rocks. The relatively high birefringence anisotropy $4.3 \%$ and the PPO are clearly controlled by the high amphibole content ( $60 \%$ of the rock). Highly anisotropic directions correspond to the foliation plane. The slight obliquity to the foliation of this girdle of strong birefringence is related to the obliquity of the amphibole LPO. The directions of low birefringence values are close to the pole of the foliation. The PPO of the fast S-waves propagating along directions of high birefringence (i.e. parallel to the foliation), are parallel to the foliation.

The following rocks, referred to as Mean Crust, Gneiss1, Gneiss2 and Schist, were computed to represent the felsic crust. Mean Crust has a mineralogical composition of the average crustal composition given by Anderson (1989). It is not a real rock but a hypothetical rock containing all crustal components in realistic proportions. This kind of synthetic sample enables an evaluation of the effect of combining numerous fabrics together (five minerals with LPO and one isotropic phase). The Gneiss1, Gneiss2 and Schist synthetic samples are combinations of four mineralogical phases (plagioclase, quartz, biotite and K-feldspar), either with an LPO described in the previous section or as an isotropic equivalent. This allows a qualitative and quantitative evaluation of the effect of both composition and petrofabric. Furthermore, for rocks containing anisotropic quartz, the effect of the $\alpha-\beta$ quartz phase transition on seismic properties may be evaluated. From these four examples several conclusions may be drawn.

(1) Birefringence and the fast shear-wave PPO have very similar 3-D variations for the different synthetic samples even if the magnitude of anisotropy varies.

(2) Shear-wave splitting is systematically maximum for waves propagating parallel or at a small angle to the foliation (less than $30^{\circ}$ ). S-waves propagating in these high birefringence directions split strongly and the fast shear-wave is systematically polarized parallel to the foliation plane. On the contrary, birefringence is extremely low (anisotropy $<1 \%$ ) for shear-waves propagating in a direction normal to the foliation plane.

(3) It seems, at least with the selected LPO, that the main crustal tectonic structure that can 
be deduced from S-wave splitting measurements is the foliation plane. Lineation seems to be a second-order phenomenon.

(4) The spatial variations of the seismic properties are axially symmetric around the $Z$ structural axis. This feature is less pronounced when numerous LPO are taken into account. For instance, Mean crust (Fig. 7(D)) has no symmetry (five LPO), whereas Schist (Fig. 7(J)) in which only the biotite LPO has been used is almost perfectly symmetric. For quartz-bearing rocks, the axial symmetry is also more visible in the $\beta$ field due to the simple birefringence pattern of the quartz LPO above the $\alpha-\beta$ transition.

(5) Biotite is clearly the controlling factor for S-wave splitting. The rock Schist, in which only the biotite LPO has been taken into account shows all the features mentioned above and a quasi-transverse isotropic symmetry. On the other hand, numerous LPO have been used for the Mean Crust and its transversely isotropic feature generated by biotite is greatly affected by the other minerals.

(6) The $\alpha-\beta$ quartz phase transition does not change the magnitude of shear-wave splitting of quartz-bearing rocks significantly. For a given hypothetical rock, the maximum birefringence anisotropy is lowered by only $0.5 \%$. Furthermore, this phase transition has little influence on the polarization plane orientations. The only detectable effect is that birefringence has a smoother pattern in the $\beta$-quartz field (here at $600^{\circ} \mathrm{C}$ ), than

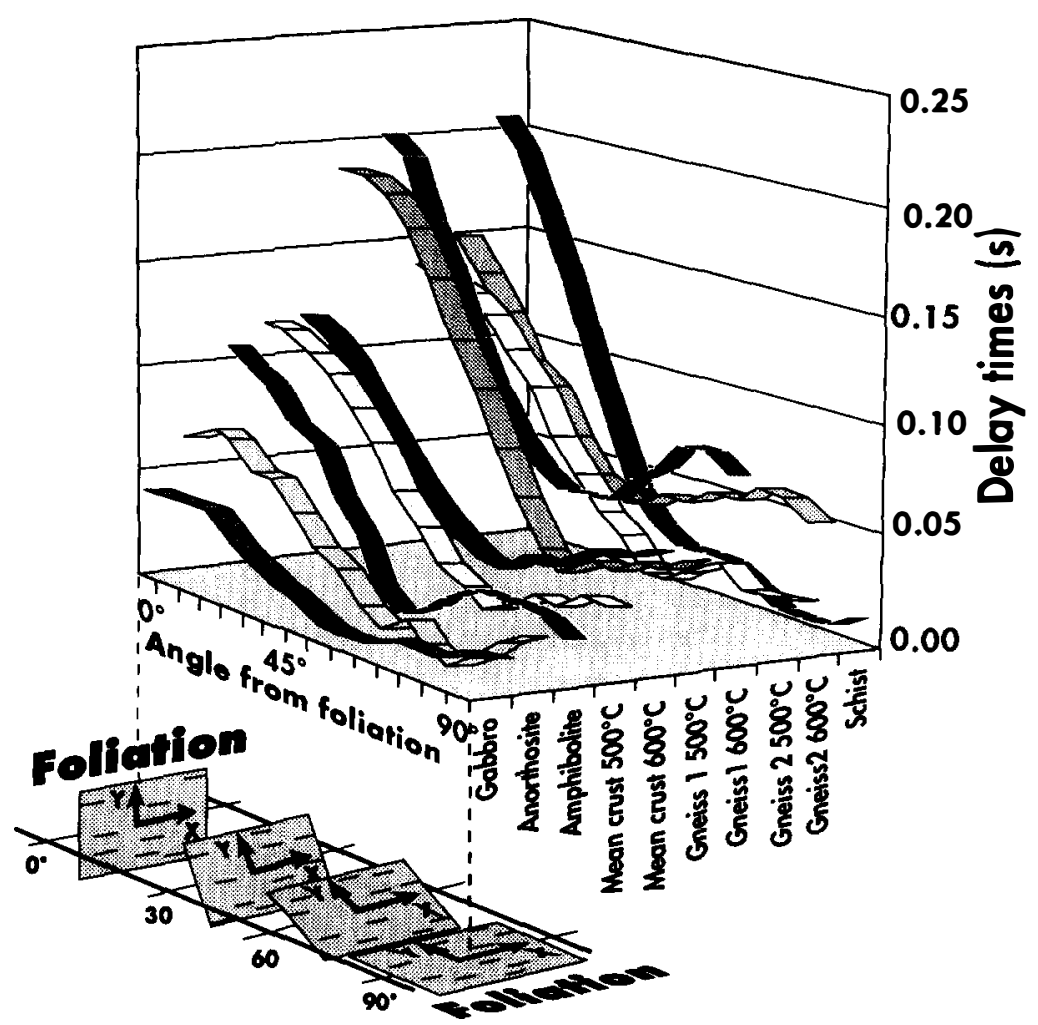

Fig. 8. Influence of the structure orientation on the delay time. These diagrams show the variations of the delay time between the two split shear-waves propagating vertically and crossing a $10 \mathrm{~km}$ thick layer composed of each of the 10 synthetic samples for various incidence angles between the seismic wave and the structural directions. (A) Variations between the $Y$ and $Z$ structural directions (angles are $0^{\circ}$ and $90^{\circ}$, respectively). Maximum splitting systematically occurs for S-waves propagating parallel to the $Y$-axis and there is almost no splitting for $S$-waves propagating normal to the foliation. (B) Variations between the $Y$ and $X$ structural directions (angle are $0^{\circ}$ and $90^{\circ}$, respectively). For more explanation see the text. 


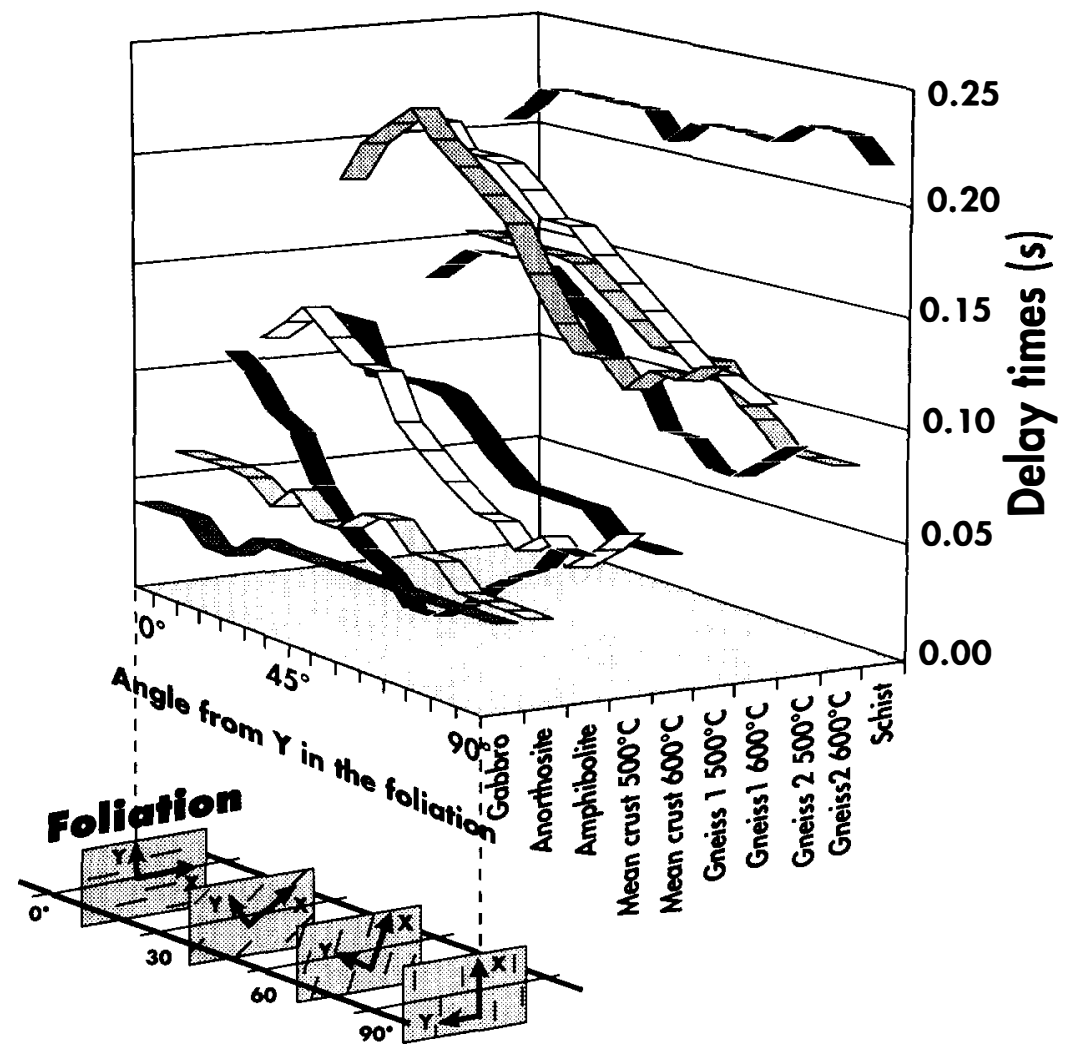

Fig. 8 (continued).

in the $\alpha$-quartz field. The transversely isotropic symmetry is higher in the $\beta$-quartz field.

(7) These calculations are in complete agreement with the birefringence obtained on similar rocks by direct laboratory velocity measurements: strong birefringence values are found for waves propagating parallel to the foliation and the fast shear wave are polarized parallel to the foliation. On the other hand, directions near the pole to the foliation are isotropic.

\subsection{Influence of the structure on SWS in crustal rocks}

From calculated crustal birefringences, the delay time between the two perpendicularly polarized waves was calculated considering an S-wave propagating vertically toward the Earth's surface and crossing a $10 \mathrm{~km}$ thick anisotropic layer with the compositions of the 10 synthetic samples cal- culated in the previous section. The variations of delay time for each layer composition as a function of the internal structure orientation (angle from the foliation or from the lineation) are presented in Fig. 8. For both diagrams, the vertical axis represents the delay time (in seconds) and each curve corresponds to a lithology. The horizontal axis corresponds to the angle between a main structural axis and the vertical.

In Fig. 8(A), we consider the $10 \mathrm{~km}$ thick layer with a horizontal lineation and a foliation rotating around it. For an incidence of $0^{\circ}$ the wave propagates vertically, parallel to the foliation plane, along the $Y$ structural direction. At an angle of $90^{\circ}$, the wave always propagates vertically but the foliation is horizontal. In this case, the wave path is parallel to the $Z$ structural axis. Large variations of delay times have been calculated, with a similar trend for the different rock types; splitting is always high (in the range of 
0.1-0.2 s) for waves propagating parallel to the foliation (i.e. when the foliation is vertical), whereas the delay time is very low (i.e. $<0.05 \mathrm{~s}$ ) for waves crossing the foliated structure at a high angle.

Figure 8(B) shows delay time variations for the layers with the various synthetic rocks' compositions, for waves with incidence between the $Y$ structural axis (angle of $0^{\circ}$ ) and the $X$-axis (angle of $90^{\circ}$ ). The wave propagates vertically and always parallel to the foliation but the orientation of the lineation varies from the horizontal $\left(0^{\circ}\right)$ to the vertical direction $\left(90^{\circ}\right)$. In this diagram, the delay time is less affected by the structure orientation than in Fig. 8(A) (i.e. the lineation orientation has less influence on the splitting than the foliation orientation).

Both diagrams show that the main structure controlling the splitting is the foliation. One can expect strong splitting for every propagation direction contained within the foliation plane and almost no splitting for $\mathrm{S}$-waves propagating in directions normal to it. In other words, one can expect a significant crustal contribution to the shear-wave splitting of teleseismic S-waves above strongly dipping structures, especially above vertical structures composed of felsic rocks such as Gneiss1 or Gneiss2.

\section{Natural cases where crustal contribution to SWS may be significant}

This section focuses on specific geological structures that may induce a crustal contribution to the splitting of vertically propagating $\mathrm{S}$-waves. The most obvious example is lithospheric strikeslip fault rooting in the upper mantle, along which vertical foliations are expected across most of the crustal thickness. A good example chosen is the San Andreas fault. The second tectonic process able to generate dipping structures on the whole crustal thickness could be the accretion. The selected example is Alaska.

\subsection{The San Andreas fault}

The San Andreas fault certainly extends down into the subcrustal lithosphere. The uppermost part of this structure $(15 \mathrm{~km})$ is seismogenic and clearly has a brittle behaviour (Dewey et al., 1989). Further down, broader zones of deformation in a more ductile regime may be expected. Under middle to lower crustal $P T$ conditions and in a strike-slip regime, new mineral phases such as phyllosilicates may lcrystallize parallel to the vertical foliation. The depth at which petrofabrics will play an important role for splitting is in fact

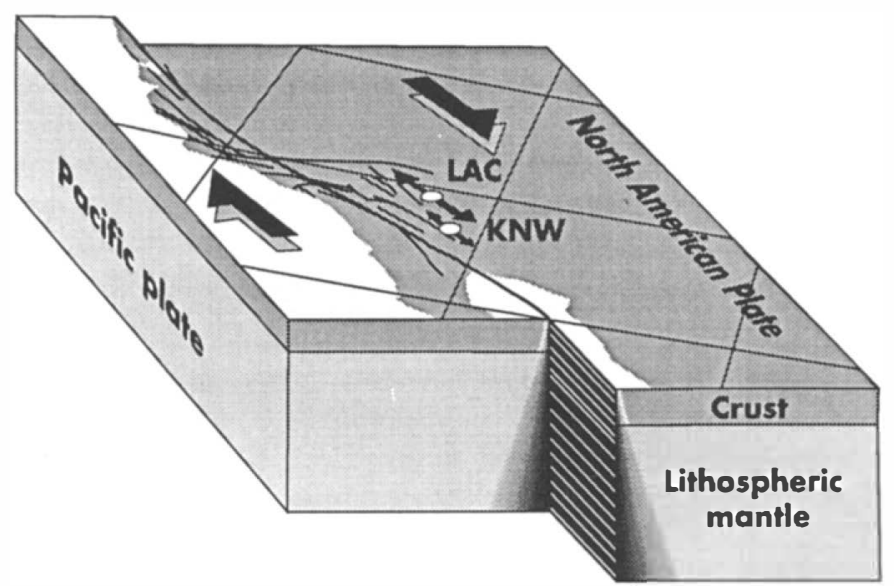

Fig. 9. Schematic block diagram of the San Andreas fault area showing the close relationship between the fault and the anisotropy orientation at the LAC and $\mathrm{KNW}$ seismic stations. 
controlled by the temperature. The lowest temperature for phyllosilicates to form occur at about $300^{\circ} \mathrm{C}$. Within a strike-slip fault, they will grow vertically and develop a foliation. For a normal geotherm, $300^{\circ} \mathrm{C}$ corresponds to about $10 \mathrm{~km}$ but in active areas where the geotherm is higher, $300^{\circ} \mathrm{C}$ may be reached at shallower depths.

Several splitting measurements have been performed on this strike-slip fault. Savage et al. (1990) measured a strong delay time (1.2 s) at the LAC station (see location on Fig. 9) using splitting of SKS-waves. The fast shear-wave was measured parallel to the strike of the fault (Fig. 9). Savage et al. relate this parallelism to the simple shear strain between the Pacific and the North American plates. For this station LAC, the results cannot invalidate the hypothesis of a crustal contribution to the splitting.

Peacock et al. (1988) and Crampin et al. (1990) analysed shear-wave splitting from local events in the Anza seismic gap. Earthquakes take place in the crust at depths down to $17 \mathrm{~km}$. Most of the stations clearly show fast shear-waves oriented north-south which are interpreted as resulting from microcracks parallel to the major in situ horizontal stress (Zoback and Zoback, 1989). For one station (KNW), the fast shear wave was clearly oblique to the maximum horizontal stress (see Fig. 9) and had the same trend as the fault $\left(\mathrm{N} 140^{\circ}\right)$. This station is located on the Hot Spring Fault where heat flow is particularly high.

An alternative interpretation is to explain such observations in terms of structures. If heat flow is high enough, as for instance in the Hot Spring area, foliation within the fault may have developed in the uppermost crustal levels and LPO may have played a dominant role in S-wave splitting. For station $\mathrm{KNW}$, the results may be interpreted in terms of a major LPO contribution to the delay time measured.

It seems reasonable to assume that we can find rocks such as Mean Crust or Gneiss2 with gneissic structure on the whole crustal scale along such strike-slip faults, except for the uppermost levels where the temperature is not high enough to allow the development of the foliation. Assuming that the crust is composed of such rocks and that the foliation is vertical on $20-30 \mathrm{~km}$ thickness, an S-wave crossing this structure will split. The delay time between the two perpendicularly polarized

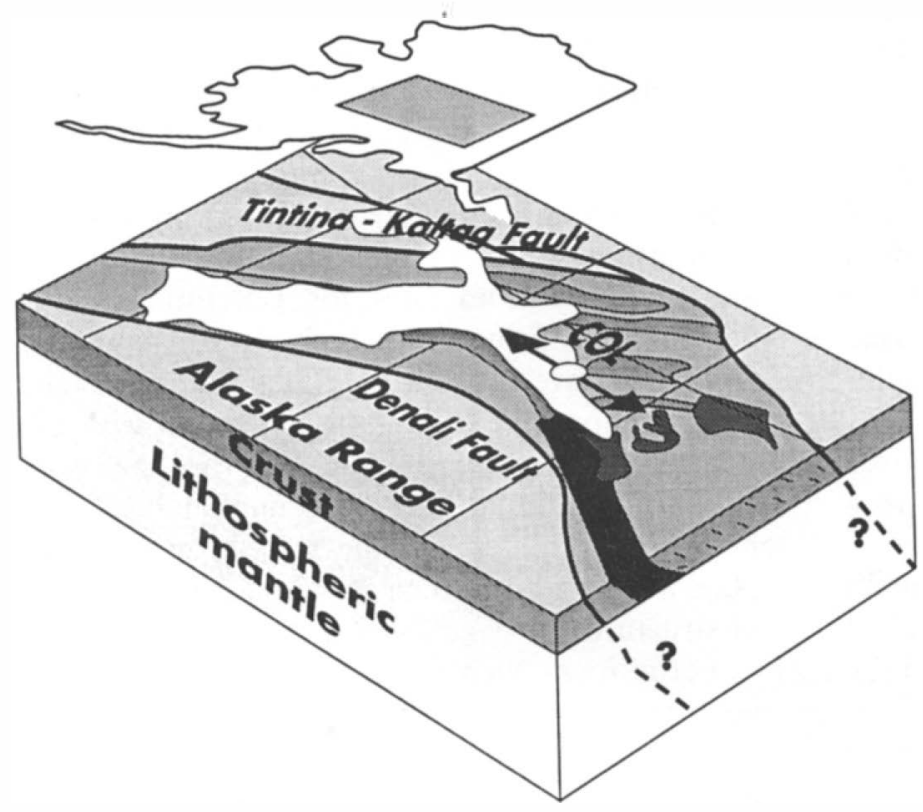

Fig. 10. Schematic block diagram of the Alaskan region around the COL station. 
shear waves could be in the range of $0.3-0.5 \mathrm{~s}$. Such significant values represent about the third to the fifth of measured SKS-wave splitting.

\subsection{The Alaskan accretion}

Alaska represents an active convergent plate boundary along which numerous terrains have been accreted (e.g. Coney and Jones, 1985). Two different modes of deformation have probably occurred. First, a simple orthogonal convergence: a block is dragged toward the continent by the subducting plate. Subsequently, when the system locks up the convergence is accommodated by lateral movement along the block boundaries. Both kinds of mechanisms may generate dipping structures. In each block, the foliation is often steeply dipping (e.g. Page et al., 1986; Goodwin et al., 1989) and rocks have metasedimentary compositions with a high phyllosilicate content. Strike-slip faults separating blocks may also be expected to have at least a crustal extent and therefore vertical structures.

Splitting measurements of SKS-waves at COL station (Silver and Chan, 1991) are characterized by a strong delay time (1.55 s) and the fast shear-wave is orientated N098 ${ }^{\circ}$. This station is close to the Denalli strike-slip fault and the Alaska Range is to the south and the TintinaKaltag strike-slip fault to the north (Fig. 10). The fast shear-wave is clearly orientated parallel to the strike of the faults. Silver and Chan interpreted this orientation as due to a subcontinental mantle deformation similar to the deformation of the crust. This is a typical case where mantle and crustal coupling may generate mantle and crustal structures having the same effect on S-wave splitting.

If we assume a crust $20-30 \mathrm{~km}$ thick composed by Gneiss1, Gneiss2 or Schist rock types with a dipping foliation in the range $60-90^{\circ}$, the crustal contribution at the COL station may be about $0.3-0.5 \mathrm{~s}$, which represents a significant fraction of the total measured delay time (the fifth to the third of the total splitting).

In other places the fast shear-wave has been measured parallel to the strike of the structure that crops out. For example, the station RSON on the Canadian Shield (Silver and Chan, 1991) exhibits a very high delay time between the two shear-waves (1.7 s) and the fast shear-wave is orientated parallel to the regional foliation that crops out. It could indicate a strong coupling between mantle and crust and a significant crustal contribution. In Shikoku Island (Japan) a high delay time has also been observed (Kaneshima and Ando, 1989) with a fast wave orientated parallel to the strike of the Sanbagawa metamorphic zone (about $\mathrm{N} 070^{\circ}$ ), which is composed of strongly anisotropic schists. Because maximum horizontal compressive stress has a more eastwest strike, it is suggested that mineral preferred orientations make a stronger contribution to the total splitting than microcracks. These are not exhaustive examples and one needs more detailed studies to better quantify the real crustal contribution to the shear-wave splitting.

\section{Conclusions}

In this paper the shear-wave properties of 10 typical crustal rocks have been modelled. We have determined delay times between the two split shear-waves crossing a layer with the 10 different lithologies. We have shown that the crust may have a significant contribution to the total splitting of teleseismic S-waves in some cases, particularly where the foliation is expected to be steeply dipping.

Mafic rocks such as pyroxene-bearing gabbros or anorthosites are moderately anisotropic. They are not good candidates for generating strong delay times. Furthermore, both birefringence and fast shear-wave PPO have no clear and systematic relationships with the fabric and hence with the structure, consequently they can not be good tectonic indicators. However, amphibolites have higher anisotropies and the fast shear-wave displays a simple pattern easier to interpret in terms of structure.

Felsic rocks such as quartz and phyllosilicatebearing gneisses or schists are good structural indicators. They are highly anisotropic and exhibit consistent relationships between structure and splitting. Time delay between the two split 
shear-waves is very high in a direction parallel to the foliation plane whereas it is very low in directions normal to it. This is in complete agreement with the measurements of shear-wave birefringence performed in the laboratory on real samples.

Fast shear-wave polarization plane orientation is controlled by the orientation of the foliation plane; the fast shear-wave travels mainly parallel to it. This is also in complete agreement with the direct laboratory measurements. Lineation is more difficult to relate to shear-wave splitting measurements. It is clearly a second-order feature compared with the foliation.

The time delay between the two split shearwaves propagating in a given direction is mainly controlled by two factors: the biotite content in the rock which controls the intrinsic maximum anisotropy and the orientation of the foliation relative to the incident wave.

The number of mineralogical phases does not greatly influence the shape of the birefringence pattern but does influence the magnitude of anisotropy.

Birefringence depends strongly on phyllosilicate content. At high phyllosilicate content, the S-wave anisotropies exhibit strong transverse isotropic patterns around the $Z$ structural axis (pole of the foliation).

In shear-wave splitting measurements above a horizontally foliated crust, a very small crustal contribution is expected, whereas above a zone of dipping foliation, the crustal contribution may reach $0.5 \mathrm{~s}$ assuming a steeply dipping foliation of felsic rocks through the entire thickness of the crust.

\section{Acknowledgements}

This study has been supported by the Accompagnement ECORS $90 / 91$ programme and by the DBT programme Thème Géodynamique. Thanks to G. Lloyd for his useful help and advice for the channelling measurements with the SEM undertaken at Leeds University (UK). Thanks to V. Babuška, D. Fountain, P. Silver and A. Vauchez for their contructive comments.

\section{References}

Aleksandrov, K.S. and Ryzhova, T.V., 1961. The elastic properties of rock forming minerals II: Layered silicates. Izv. Acad. Sci. USSR, Geophys. Phys. Solid Earth, 1165-1168.

Aleksandrov, K.S., Alchikov, U.V., Belikov, B.P., Zaslavskii, B.I. and Krupnyi, A.I., 1974. Velocities of elastic waves in minerals at atmospheric pressure and increasing precision of elastic constants by means of EVM (in Russian). Izv. Acad. Sci. USSR, Geol. Ser., 10: 15-24.

Anderson, D.L., 1989. Theory of the Earth. Blackwell Scientific, Oxford, 366 pp.

Barruol, G. and Kern, H., 1993. P and S-waves velocities and shear-wave splitting in the lower crustal/upper mantle transition (Ivrea Zone). Experimental and calculated data. Geophys. J. Int., submitted:

Barruol, G. and Mainprice, D., 1993. 3D seismic velocities calculated from LPOs and reflectivity of a lower crustal section-Example of the Val Sesia (Ivrea Zone, Northern Italy). Geophys. J. Int., in press.

Barruol, G., Mainprice, D. and Kern, H., 1991. Quantification of 3D seismic properties of amphibolitic facies lower crustal section transected by a ductile shear zone. The Saint Barthélémy massif (Northern Pyrénées, France). E.U.G VI, Strasbourg.

Barruol, G., Mainprice, D., Kern, H., Saint Blanquat, M. and Compte, P., 1992. 3D seismic study of a ductile shear zone from laboratory and petrofabric data (Saint Barthélémy Massif, Northern Pyrénées, France). Terra Nova, 4: 63-76.

Benn, K. and Mainprice, D., 1989. An interactive program for determination of plagioclase crystal axes orientations from U-stage measurements: an aid for petrofabric study. Comput. Geosci., 15: 1127-1142.

Bouchez, J.L., 1977. Plastic deformation of quartzites at low temperatures in an area of natural strain gradient. Tectonophysics, 39: 25-50.

Boudier, F., 1978. Structure and petrology of the Lanzo massif (Piedmont Alps). Geol. Soc. Am. Bull., 89: 15741591.

Christensen, N.I., 1966. Shear wave velocities in metamorphic rocks at pressures to 10 Kilobars. J. Geophys. Res., 71: 3549-3556.

Coney, P.J. and Jones, D.L., 1985. Accretion tectonics and crustal structure in Alaska. Tectonophysics, 119: 265-283.

Crampin, S., 1985. Evaluation of anisotropy by shear-wave splitting. Geophysics, 50: 142-152.

Crampin, S., Booth, D.C., Evans, R., Peacock, S. and Fletcher, J.B., 1990. Changes in shear-wave splitting at Anza near the time of the North Palm Springs earthquake. J. Geophys. Res., 95: 11 197-11 212.

Crosson, R.S. and Lin, J.W., 1971. Voigt and Reuss prediction of anisotropic elasticity of dunite. J. Geophys. Res., 76: 570-578.

Dewey, J.W., Hill, D.P., Ellsworth, W.L. and Engdahl, E.R., 1989. Earthquakes, faults, and the seismotectonic framework of the contiguous United States. In: L. Pakister and W. Mooney (Editors), Geophysical Framework of the 
United States. Geological Society of America, Vol. 172, pp. 541-575.

Fountain, D.M. and Christensen, N.I., 1989. Composition of the continental crust and upper mantle; a review. In: L. Pakister and W. Mooney (Editors), Geophysical Framework of the United States. Geological Society of America, Vol. 172, pp. 711-742.

Fountain, D.M., Hurich, C.A. and Smithson, S.B., 1984. Seismic reflectivity of mylonite zones in the crust. Geology, 12: 195-198.

Goodwin, E.B., Fuis, G.S., Nokleberg, W.J. and Ambos, E.L., 1989. The crustal structure of the Wrangellia terrane along the east Glenn highway, eastern-southern Alaska. J. Geophys. Res., 94: 16 037-16 057.

Ji, S., Mainprice, D. and Boudier, F., 1988. Sense of shear in high temperature movement zones from the fabric asymmetry of plagioclase feldspars. J. Struct. Geol., 10: 73-81.

Kaneshima, S. and Ando, M., 1989. An analysis of split shear waves observed above crustal and uppermost mantle earthquakes beneath Shikoku, Japan: implications in effective depth extent of seismic anisotropy. J. Geophys. Res., 94: 14 077-14092.

Kern, H., 1990. Laboratory seismic measurements: an aid in the interpretation of seismic field data. Terra Nova, 2: 617-628.

Kern, H. and Wenk, H.R., 1990. Fabric-related velocity anisotropy and shear-wave splitting in rocks from Santa Rosa mylonite zone, California. J. Geophys. Res., 95: $11213-11223$

Kern, H., Schmidt, R. and Popp, T., 1991. The velocity and deinsity structure of the $4000 \mathrm{~m}$ crustal segment at the KTB drilling site and their relationship to lithological and microstructural characteristics of the rocks: an experimental approach. Sci. Drilling, 2: 130-145.

Lloyd, G.E. and Hall, M.G., 1981. Application of scanning electron microscopy to the study of deformed rocks. Tectonophysics, 78: 687-698.

Lloyd, G.E., Ferguson, C.C. and Law, R.D., 1987. Discriminatory petrofabric analysis of quartz rocks using SEM electron channelling. Tectonophysics, 135: 243-249.

Mainprice, D., 1990. A FORTRAN program to calculate seismic anisotropy from the lattice preferred orientation of minerals. Comput. Geosci., 16: 385-393.

Mainprice, D., Humbert, M. and Wagner, F., 1990. Phase transformations and inherited lattice preferred orientation: Implications for seismic properties. Tectonophysics, 180: 213-228.

McDonough, D.T. and Fountain, D.M., 1988. Reflection characteristics of a mylonite zone based on compressional waves velocities of rock samples. Geophys. J., 93: 547-558.

McNamara, D.E., Owens, T.J., Zandt, G. and Randall, G.E., 1989. Evidence for azimuthal anisotropy in the Basin and Range province: implications for lower crustal properties. Geol. Soc. Am. Abstr. Program, 21: 321.

Mercier, J.C., 1985. Olivine and pyroxenes. In: H.-R. Wenk (Editor), Preferred orientation in deformed metals and rocks: An introduction to modern texture analysis. Academic Orlando, pp. 407-430.
Page, R.A., Plafker, G., Fuis, G.S., Nokleberg, W.J., Ambos, E.L., Mooney, W.D. and Campbell, D.L., 1986. Accretion and subduction tectonic in the Chugach mountains and Copper river basin, Alaska: Initial results of the trans Alaska crustal transect. Geology, 14: 501-505.

Peacock, S., Crampin, S., Booth, C. and Fletcher, J.B., 1988. Shear wave splitting in the Anza seismic gap, southern California: temporal variations as possible precursors. J. Geophys. Res., 93: 3339-3356.

Peselnick, L., Nicolas, A. and Stevenson, P.R., 1974. Velocity anisotropy in a mantle peridotite from the Ivrea Zone: Application to upper mantle anisotropy. J. Geophys. Res., 79: $1175-1182$.

Saint Blanquat, M., 1990. Petrological argument for high temperature extensional deformation in the Pyrenean Variscan crust (Saint Barthélémy Massif, Ariège, France). Tectonophysics, 177: 245-262.

Savage, M.K., Silver, P.G. and Meyer, R.P., 1990. Observations of teleseismic shear wave splitting in the Basin and Range from portable and permanent stations. Geophys. Res. Lett., 17: 21-24.

Schmid, S.M. and Casey, M., 1986. Complete fabric analysis of some commonly observed quartz c-axis patterns. In: H.C. Heard and B.E. Hobbs (Editor), Mineral and Rock Deformation: Laboratory Studies-The Paterson Volume. AGU Monogr. 36, AGV, Washington, DC, pp. 263-286.

Seront, B., Mainprice, D. and Christensen, N.I., 1993. A determination of the 3-dimensional seismic properties of an anorthosite-Comparison between values calculated from petrofabric and direct laboratory measurements. J. Geophys. Res., 98: 2209-2221.

Siegesmund, S. and Kruhl, J.H., 1991. The effect of plagioclase textures on velocity anisotropy and shear-wave splitting at deeper crustal levels. Tectonophysics, 191: 147-154.

Siegesmund, S., Takeshita, T. and Kern, H., 1989. Anisotropy of $\mathrm{Vp}$ and $\mathrm{Vs}$ in an amphibolite of the deeper crust and its relationship to the mineralogical, microstructural and textural characteristics of the rock. Tectonophysics, 157: 2538.

Silver, P.G. and Chan, W.W., 1991. Shear wave splitting and subcontinental mantle deformation. J. Geophys. Res., 96: 16 429-16 454.

Vaughan, M.T. and Guggenheim, S., 1986. Elasticity of muscovite and its relationship to crystal structure. J. Geophys. Res., 91: 4657-4664.

Weidner, D.J., Wang, H. and Ito, J., 1978. Elasticity of orthoenstatite. Phys. Earth Planet. Inter., 17: 7-13.

Zoback, M.L. and Zoback, M.D., 1989. Tectonic stress field of the continental United States. In: L. Pakister and W. Mooney (Editors), Geophysical framework of the United States. Trans. ed. Geological Society of America, Vol. 172, pp. 523-539.

Zubov, V.G. and Firsova, M.M., 1962. Elastic properties of quartz near the $\boldsymbol{\alpha}-\boldsymbol{\beta}$ transition. Soviet Phys.- Cryst., 7: 374-376. 